\title{
Movement patterns of three arboreal primates in a Neotropical moist forest explained by LiDAR-estimated canopy structure
}

\author{
Kevin A. McLean • Anne M. Trainor • Gregory P. Asner • \\ Margaret C. Crofoot • Mariah E. Hopkins • Christina J. Campbell • \\ Roberta E. Martin - David E. Knapp • Patrick A. Jansen
}

Received: 26 September 2015/ Accepted: 14 March 2016/Published online: 29 March 2016

(C) Springer Science+Business Media Dordrecht 2016

\begin{abstract}
Context Many arboreal mammals in Neotropical forests are important seed dispersers that influence the spatial patterns of tree regeneration via their movement patterns, which in turn are determined by the canopy structure of the forest itself. However, the relationship between arboreal mammal movement and canopy structure is poorly understood, due in large part to the complexity of quantifying arboreal habitat structure.
\end{abstract}

Electronic supplementary material The online version of this article (doi:10.1007/s10980-016-0367-9) contains supplementary material, which is available to authorized users.

\section{K. A. McLean $(\square)$}

Greeley Memorial Laboratory, Yale School of Forestry and Environmental Studies, 370 Prospect Street,

New Haven, CT 06511, USA

e-mail: kevin.mclean@yale.edu

K. A. McLean - M. C. Crofoot · P. A. Jansen

Smithsonian Tropical Research Institute, Balboa, Panama

A. M. Trainor

The Nature Conservancy, 4245 Fairfax Dr., Arlington, VA 22203, USA

G. P. Asner · R. E. Martin · D. E. Knapp

Department of Global Ecology, Carnegie Institution for

Science, 260 Panama St., Stanford, CA 94305, USA

\section{C. Crofoot}

Department of Anthropology, University of California Davis, 1 Shields Ave., Davis, CA 95616, USA
Objectives We relate detailed movement trajectories of three sympatric primate species to attributes of canopy structure derived from airborne light detection and ranging (LiDAR) in order to understand the role of structure in arboreal movement in the tropical moist forest of Barro Colorado Island, Panama.

Methods We used high-resolution LiDAR to quantify three-dimensional attributes of the forest canopy of the entire island, high-resolution GPS tracking to map the movement patterns of the monkey species, and step selection functions to relate movement decisions to canopy attributes.

\author{
M. E. Hopkins \\ Department of Anthropology, University of Texas at \\ Austin, SAC 4.102, 2201 Speedway Stop C3200, Austin, \\ TX 78712, USA \\ C. J. Campbell \\ Department of Anthropology, California State \\ University - Northridge, 18111 Nordhoff Street, \\ Northridge, CA 91330, USA \\ P. A. Jansen \\ Department of Environmental Sciences, Wageningen \\ University, P.O. Box 47, 6700AA Wageningen, The \\ Netherlands
}


Results We found that movement decisions were correlated with canopy height and distance to gaps, which indicate forest maturity and lateral connectivity, in all three species. In the two faster-moving species, step selection was also correlated with the thickness of the crown layer and the density of vegetation within the crown.

Conclusions The correlations detected are fully in line with known differences in the locomotor adaptations and movement strategies of the study species, and directly reflect maximization of energetic efficiency and ability to escape from predators. Quantification of step selection in relation to structure thus provides insight into the ways in which arboreal animals use their environment.

Keywords Alouatta palliata Ateles geoffroyi .

Arboreal habitat $\cdot$ Canopy structure $\cdot$ Cebus capucinus · LiDAR · Movement ecology · Primate . Step selection function

\section{Introduction}

The canopy of Neotropical forests is home to the highest diversity of non-volant arboreal mammals in the world, with over $75 \%$ of all vertebrates and $60 \%$ of mammal species at least partially occupying this space (Kays and Allison 2001; Malcolm 2004). Many of these mammals feed on fruits and fulfill important roles as seed dispersers, defecating seeds below their sleeping and foraging sites as well as along the movement trajectories between these sites. Thus, the amount of seed fall from the forest canopy and spatial patterns of seedling recruitment on the forest floor may depend heavily on the movements of arboreal dispersers (Russo and Augspurger 2004; Russo et al. 2006; Wehncke and Domínguez 2007). Understanding how canopy-dwelling animals disperse seeds requires mechanistic models for predicting how species move through the canopy (Muller-Landau and Hardesty 2005), which is a largely unknown function of the canopy structure of the forest itself. The amount of seed rain that a given patch of forest receives could thus directly depend on the structure of the canopy above. Beyond seed dispersal, investigation of species distribution, habitat suitability, and other modeling approaches that help define conservation status are also aided by intimate understanding of the relationship between movement and the surrounding environment (Guisan and Thuiller 2005; Hirzel et al. 2006). However, the ways that mammals differentially utilize the forest canopy remains poorly known due in large part to the difficulty associated with characterizing and quantifying the structural complexity of canopies (Carroll 1980).

Arboreal mammals show preference for canopy features that aid movement and provide foraging resources (Davies and Asner 2014). Mature forests often provide the most suitable habitat for arboreal fauna, particularly in the Neotropics. For example, tall canopies - a proxy for forest maturity-were a strong predictor of habitat use by Bald-faced saki monkeys (Pithecia irrorata) in the Peruvian Amazon (Palminteri et al. 2012). An enclosed canopy provides ample horizontal substrate for arboreal movement of species for which vertical movement between the forest floor and the canopy is often risky and energetically disadvantageous (Pontzer and Wrangham 2004; Makin et al. 2012). Tree fall gaps, in contrast, present obstacles for lateral movement that will be circumvented by canopy fauna rather than crossed at altitude or on the ground (Emmons and Gentry 1983).

The relationship between forest landscape features and movement behavior has been explored in arboreal mammals, including both Old and New World primates (Emmons and Gentry 1983; Cannon and Leighton 1994; Di Fiore and Suarez 2007; Hopkins 2011). The complexity of negotiating 3-D movement paths through the forest canopy, along with the need to maintain spatial memory of fruiting trees, has been credited for the high cognitive capacity of arboreal mammals (Emery and Clayton 2004). Thus, arboreal primates are thought to maintain mental maps of resource locations in order to achieve route-based movement (Milton 1981; Asensio et al. 2011). Hopkins (2011) revealed that the location of repeatedly used pathways for Mantled howler monkeys (Alouatta palliata) was driven by canopy structure, resource location, and topography. Using detailed forest measurements by trained observers, the relationship between forest structure and movement was established at the scale of the 50-ha experimental plot. This seminal work incites questions of how canopy structure affects movement behavior for the rest of the arboreal community at the landscape scale.

Pioneering studies have established the relationship between movement decisions and canopy structure, 
but the rapidly growing field of movement ecology has paid little attention to arboreal habitat and species. This is due at least in part to the issue of scale that is so often encountered in ecology (Levin 1992), with the added challenge of the dimensionality of arboreal habitat. That is, the scales at which canopy properties were measured in past studies did not align with the spatial and dimensional scale of behavior (e.g. movement decisions, foraging, ranging). Percent cover by height class, the measure that is needed to also characterize vertical structure, can be measured manually from the ground only at small spatial scales (Anderson-Teixeira et al. 2015). Ground-based airborne light detection and ranging (LiDAR), a technology based on emitted laser pulses, provides a more efficient method to characterize 3-D structure of forest, but even with this technique it is logistically infeasible to conduct surveys at the spatial extents over which most mammal species move. Conversely, satellite-based remote-sensing technology can provide imagery for large areas-even at fine scales $\left(0.6 \mathrm{~m}^{2}\right)$ - but again cannot resolve the vertical complexity of tropical forests.

Airborne LiDAR has provided a new way to map the 3-D architecture of forest canopies (Asner et al. 2007). LiDAR has already proven its unique ability to estimate tropical forest carbon stocks (Mascaro et al. 2010; Asner et al. 2011), and shows similar promise for relating variation in forest canopy structure to animal movement (Palminteri et al. 2012; Trainor et al. 2013; Simonson et al. 2014; Davies and Asner 2014). LiDAR data can be combined with animal movement data using statistical tools for geospatial movement analyses to examine how arboreal structure affects movement decisions at large spatial scales (Davies and Asner 2014).

In this study, we relate detailed movement trajectories for three sympatric primate species with distinct locomotor adaptations and behaviors to LiDARderived attributes of canopy structure. We used highresolution LiDAR to quantify three-dimensional attributes of the forest canopy of the entire island, high-resolution global positioning system unit (GPS)tracking to map the movement patterns of the monkey species, and step selection functions (SSF) to relate movement decisions to canopy attributes. We address two central questions:

1. How are structural properties in forest canopies associated with different primate species movement behaviors? In order to address this question we identified structural properties as measured by airborne LiDAR which influenced movement routes by three focal primate species using step selection models.

2. How important is forest structure in determining movement routes? To answer this question, we used the performance of the step selection models under cross-validation to reveal the contribution of forest structure to step selection models.

\section{Materials and methods}

Study site

Data were collected at Barro Colorado Island (BCI), a 1560-ha nature preserve established in 1914. The topography of the island includes a plateau in the center of the island, with steep escarpments carved by streambeds fanning outward to the surrounding lake. The vegetation is semi-deciduous tropical moist forest with a distinct dry season (mid-December to midApril). The highest trees reach upwards of $40 \mathrm{~m}$, though average height of the canopy varies distinctly based on the age of the forest. Regrowth from historical logging practices created sections of the forest that vary in age. The southwestern half of the island has old-growth forest with a high and clearly defined, densely vegetated canopy that shades out most understory and ground-level growth. The northeastern half of the island has late-secondary forest that tends to have a lower canopy with few emergent crowns and more dense vegetation throughout the vertical profile (i.e. from canopy to understory to ground).

\section{Focal species}

Movement behavior was assessed for three species, White-faced capuchin monkeys (Cebus capucinus), Mantled howler monkeys (Alouatta palliata), and Black-handed spider monkey (Ateles geoffroyi), all of which are large-bodied (mean body mass (female/male): $2.54 / 3.68, \quad 5.35 / 7.15, \quad 7.29 / 27.78 \mathrm{~kg}$, respectively; Smith and Jungers 1997) and primarily arboreal. Approximately 15-20 groups of capuchin monkeys (Crofoot et al. 2011) and $\sim 60$ groups of 
howler monkeys (Milton et al. 2005) exist on BCI, each of which maintains a defined territory in relation to neighboring groups. While these territories are often highly overlapping, intraspecific social factors (i.e. interactions with neighboring social groups) may constrain the movement decisions of these species (Crofoot 2007; Hopkins 2013). There is only one social group of spider monkeys on the island, and their home range and movements are likely unconstrained by social factors. All three species have been observed in all vertical layers of the forest, including the ground, though use of aboveground strata is most common for all.

The three focal species have notably different locomotor adaptation that may affect their movement behavior (Chapman 1988). As semi-brachiators, spider monkeys have specialized shoulder morphology that allows them to 'swing' through the trees allowing for crossing of larger gaps. In contrast, capuchin and howler monkeys are arboreal quadrupeds, which climb and walk along branches and jump from one tree to the next, relying more heavily on reaching and climbing. Both spider and howler monkeys have a derived, prehensile tail that also aids in arboreal locomotion and foraging (e.g. crossing larger gaps, reaching further for fruit). In addition, the structural environment in which semi-brachiation is most efficient is likely more specific (dense, mature canopy) than for the more generalized movement strategies of capuchin and howler monkeys. Due to the many differences in locomotor strategies among the three focal species, the definition of "connectivity" may also vary for each species. Thus, we expected interspecific variation in how forest structure is used during movement. However, any similarity the structural features that influence movement for the three focal species may provide valuable insight for defining and evaluating habitat suitability for arboreal mammals in general.

\section{Animal movement patterns}

Each of the three primate species in our study has distinctive movement characteristics that can be attributed to physiological, behavioral, and social factors. The diversity of movement strategies represented by the focal species may provide insight into how canopy structure is broadly used by the arboreal mammal community. Spider monkeys and capuchin monkeys both maintain high-energy frugivorous and omnivorous diets, which supply ample metabolic energy for high-speed movement that covers great distances throughout the day. Meanwhile, howler monkeys tend to have much more limited movement speed and cover a shorter distance in a day due in large part to its lower-energy folivorous diet.

We analyzed movement patterns for the three monkey species from movement data compiled from previous studies. We used telemetry data obtained using an e-OBS GPS collar (http://www.e-obs.de) in 2009 from a high-ranking adult female capuchin monkey on the northeast part of BCI (Crofoot unpubl. data; archived in movebank.org). Capuchin monkeys live in stable social groups that move together as a unit. Females stay in the same group their entire lives, and thus a collared adult female is a good marker for the location of the group (Crofoot et al. 2008). GPS fixes were obtained every 10 min during $12 \mathrm{~h}$ a day for 3 months. Fixes that were clearly erroneous (i.e. missing time steps, went over water) were removed. The final data set included 2998 fix points. Spider monkey movement data were collected in 2011 using an e-OBS GPS collar (http://www.e-obs.de) on a subadult female (Campbell unpubl. data; archived in movebank.org). GPS fixes were 15 min apart and were collected from roughly sunrise to sunset (known activity period) for 6 months. The points that appeared to be erroneous were removed, though these were few $(<10 \%)$. The final data set contained 5537 points. GPS collar error for both capuchin and howler monkeys is estimated at $<2 \mathrm{~m}$. While 3-D fixes were recorded by the collar, the enclosed canopy of tropical forests may obstruct GPS fixes enough to produce unreliable height values (Di Orio et al. 2003; Kays pers. comm.), so we relied only on 2-D positions from collars. Movement data of howler monkey were collected in 2005 and 2006 by physical follows of one social group by an observer, taking waypoints using GPS receiver (Garmin V500) and georeferenced trees, for 7-12 consecutive days per month across a full year (Hopkins 2011). GPS fixes were $10 \mathrm{~min}$ apart and data were collected only during observed activity times (after waking, before sleep). The final data set included 1600 points.

Movement data were summarized using three basic metrics to provide a generalized profile of the movement behavior of each species (Fig. 1): average speed per time interval ("step"), mean daily trajectory length, and area of the observed range (minimum 
convex polygon surrounding total observed movement trajectory). Length and turning angle were calculated for each step in movement paths using "pathmetrics" in the Geospatial Modeling Environment (GME; spatialecology.com). Histograms of the pathmetrics were generated using the Freedman-Diaconis rule, which uses the interquartile range to determine histogram bin size, ideal for data sets with $n>200$ (Thurfjell et al. 2014). To correct for GPS error and focus analysis on periods of active movement, all step lengths $<10 \mathrm{~m}$ were excluded from the step-length distributions. While some studies generate up to 200 available steps for each observed step, Thurfjell et al. (2014) recommend generating smaller samples (1-10) of available steps in studies with large sample sizes (e.g. thousands observed steps) in order to prevent oversampling of the surrounding area.

\section{Canopy structure}

We used airborne light detection and ranging (LiDAR) to map the 3-D structure of the forest canopy across nearly the entire island. LiDAR operates by sending pulses of light and measuring the speed at which these pulses return to a sensor. Airborne LiDAR has been used to quantify aboveground forest biomass in temperate forests for more than a decade (Vierling et al. 2008; Palminteri et al. 2012), but the use of
LiDAR in tropical forests has been quite limited because the densely vegetated canopies of these forests create a barrier impenetrable by many early LiDAR designs. However, new, high-resolution, multi-return LiDAR technology can now sense the three-dimensional structure of even densely vegetated tropical forests, far beyond the capabilities of commercial LiDAR (Pontzer and Wrangham 2004; Asner et al. 2012; Makin et al. 2012). Airborne LiDAR data were collected in September 2009 using an aircraft operated by the Carnegie Airborne Observatory (CAO-1; Asner et al. 2007). Collected $2000 \mathrm{~m}$ above ground level, the data include $98 \%$ coverage of BCI (Mascaro et al. 2010; Asner et al. 2011).

We selected forest structure attributes known or expected to affect the movement behavior of nonvolant arboreal mammals for our analysis (Di Fiore and Suarez 2007; Hopkins 2011; Palminteri et al. 2012, Table 1). Forest structure attributes were extracted from processed LiDAR data collected by the Carnegie Airborne Observatory, as described in Mascaro et al. (2010). LiDAR points were used to estimate canopy height at a $1.2-\mathrm{m}^{2}$ resolution and relative vegetation density by height at a $10-\mathrm{m}^{2}$ resolution. We used these vegetation density data to derive nine forest structure variables estimating lateral connectivity, substrate availability, and forest maturity (Table 1). We used distance to gaps in the canopy

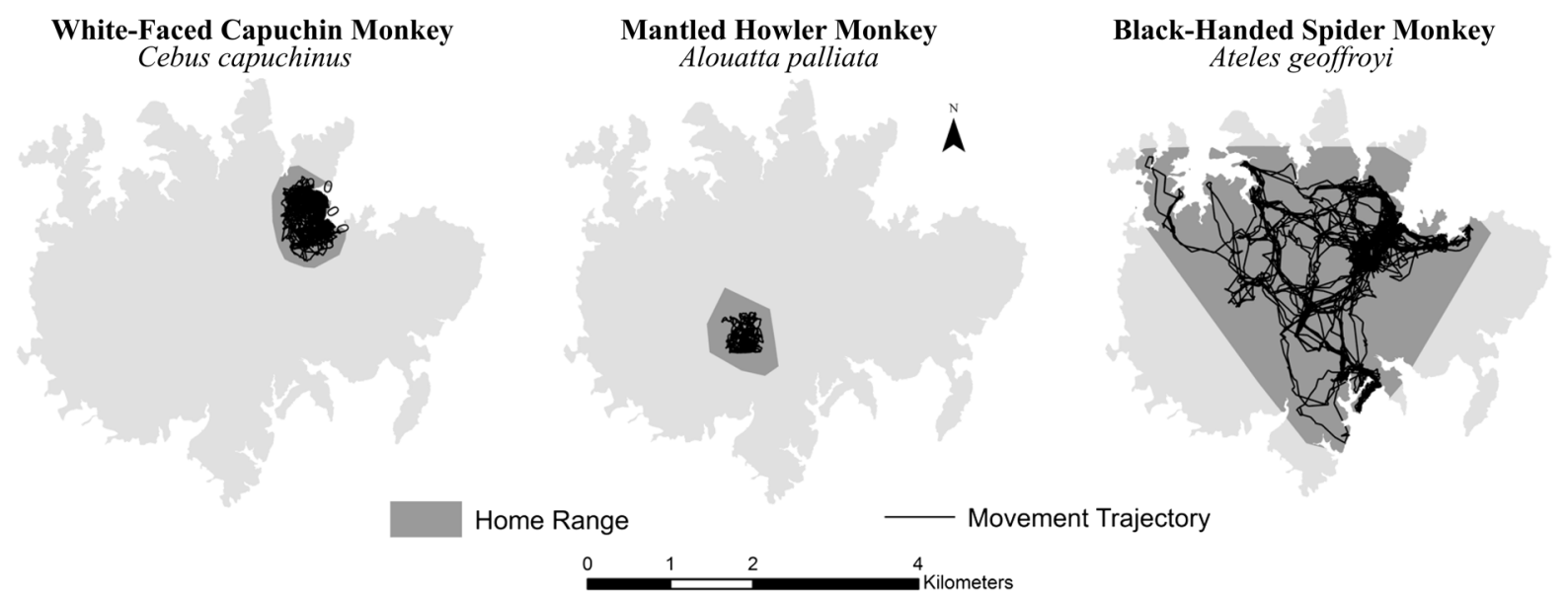

Fig. 1 Movement profiles of three monkey species on Barro Colorado Island, Panama, derived from tracking data. The spider monkey (1 GPS collared individual) had a largely unconstrained home range and move rapidly over long distances each day. The capuchin monkey (1 GPS collared individual) also moved rapidly over long distances, but have a much more constrained home range. The howler monkey (ground-based GPS tracking of group movement) had the most constrained home range and move shorter distances at much slower rates than the other two species. The profiles align with the conventional characteristics assigned to each species 
calculated from the canopy height data to represent lateral connectivity. To account for variation among primate species, we selected two Euclidean distance threshold values that correspond the lowest height each primate species is typically observed (personal observations from M. Crofoot, C. Campbell, M. Hopkins); canopy height less than $5 \mathrm{~m}$ (gap5 m) and less than $8 \mathrm{~m}$ (gap8m). Crown Thickness (CrTh) and Crown Density (CrDen) represented substrate availability; we calculated both from the aboveground biomass data (Fig. 2). Canopy Height (canht), Top of Crown (Top), and Height of Maximum Crown Density all represented forest maturity.

\section{Modeling}

Characterization of movement relies on the assumption that animals make decisions based on variability in environmental conditions along their movement paths (Zeller et al. 2012). Thus, detection of spatial heterogeneity in the environment at a scale congruent with GPS telemetry fixes is a critical component in modeling movement. We used step selection functions (SSF) to determine how movement patterns were correlated with canopy structure. SSF belongs to the family of modeling techniques to assess selection known as resource selection function (RSF) analysis. When fix points in movement data have short, regular time steps (i.e. high temporal resolution) as in our case, SSFs provide a means of parsing out individual movement decisions relative to random locations in the environment (Milton 1981; Boyce et al. 2002; Asensio et al. 2011; Zeller et al. 2012; Squires et al. 2013). This approach uses a case-control (matched pair) conditional logistic regression and considers every used step (case) in relation to a defined number of available (control) steps. SSF is ideal for movement data that are recorded at regular, frequent intervals. To determine whether selection occurs on a step-by-step basis (i.e. on the scale at which actual movement decisions are made), the case-control conditional logistic approach examines each individual observed step (where it went) and how it relates to its surrounding available steps (where it could have gone).

Following recommendations by Thurfjell et al. (2014), five available steps were generated for every observed step from the distribution of turning angles and step lengths of the observed steps, and the length-

Table 1 LiDAR-derived measures of forest structure corresponded to lateral connectivity, forest maturity, and substrate availability

\begin{tabular}{|c|c|c|c|c|c|}
\hline $\begin{array}{l}\text { Habitat } \\
\text { property }\end{array}$ & Variable & Name & ${ }^{\mathrm{a} O r i g i n}$ & $\begin{array}{l}\text { Resolution } \\
\left(\mathrm{m}^{2}\right)\end{array}$ & Description \\
\hline \multirow[t]{2}{*}{$\begin{array}{l}\text { Lateral } \\
\text { connectivity }\end{array}$} & $\begin{array}{l}\text { Distance to gap } \\
(5 \mathrm{~m})\end{array}$ & gap $5 m$ & $\mathrm{TCH}$ & 1.2 & $\begin{array}{l}\text { Distance to gap in canopy. Euclidean distance from } \\
\text { vegetation } 5 \mathrm{~m} \text { in height or less. }{ }^{\mathrm{b}} \text { High collinearity with } \\
\text { gap } 8 \mathrm{~m}\end{array}$ \\
\hline & $\begin{array}{l}\text { Distance to gap } \\
(8 \mathrm{~m})\end{array}$ & gap $8 m$ & $\mathrm{TCH}$ & 1.2 & $\begin{array}{l}\text { Distance to gap in canopy. Euclidean distance from } \\
\text { vegetation } 8 \mathrm{~m} \text { in height or less. }{ }^{\mathrm{b}} \text { High collinearity with } \\
\text { gap } 5 \mathrm{~m}\end{array}$ \\
\hline \multirow[t]{3}{*}{$\begin{array}{l}\text { Forest } \\
\text { maturity }\end{array}$} & Canopy height & canht & $\mathrm{TCH}$ & 1.2 & $\begin{array}{l}\text { Maximum height of vegetation. Reported as top-of-canopy } \\
\text { height by Mascaro et al. (2010). }{ }^{\mathrm{b}} \text { High collinearity with Top }\end{array}$ \\
\hline & $\begin{array}{l}\text { Maximum crown } \\
\text { density }\end{array}$ & $M C D$ & $\mathrm{ACD}$ & 10 & Maximum density of a $1-\mathrm{m}$ slice within the crown \\
\hline & $\begin{array}{l}\text { Height of } \\
\text { maximum } \\
\text { crown density }\end{array}$ & $H t M C D$ & $\mathrm{ACD}$ & 10 & Height of MCD slice \\
\hline \multirow{4}{*}{$\begin{array}{l}\text { Substrate } \\
\text { availability }\end{array}$} & Crown density & CrDen & $\mathrm{ACD}$ & 10 & Density of vegetation within the canopy crown \\
\hline & Top of crown & Top & $\mathrm{ACD}$ & 10 & $\begin{array}{l}\text { Maximum height slice with vegetation in canopy crown } \\
{ }^{\mathrm{b}} \text { High collinearity with canht }\end{array}$ \\
\hline & Bottom of crown & Bot & $\mathrm{ACD}$ & 10 & Height of lower boundary of canopy crown \\
\hline & Crown thickness & CrTh & $\mathrm{ACD}$ & 10 & Height between bottom and top of crown \\
\hline
\end{tabular}

a Structural variables were calculated from top-of-canopy height (TCH) and aboveground canopy density (ACD) described by Mascaro et al. (2010)

b Variables that were highly collinear were not used in the same model (see Table S1) 


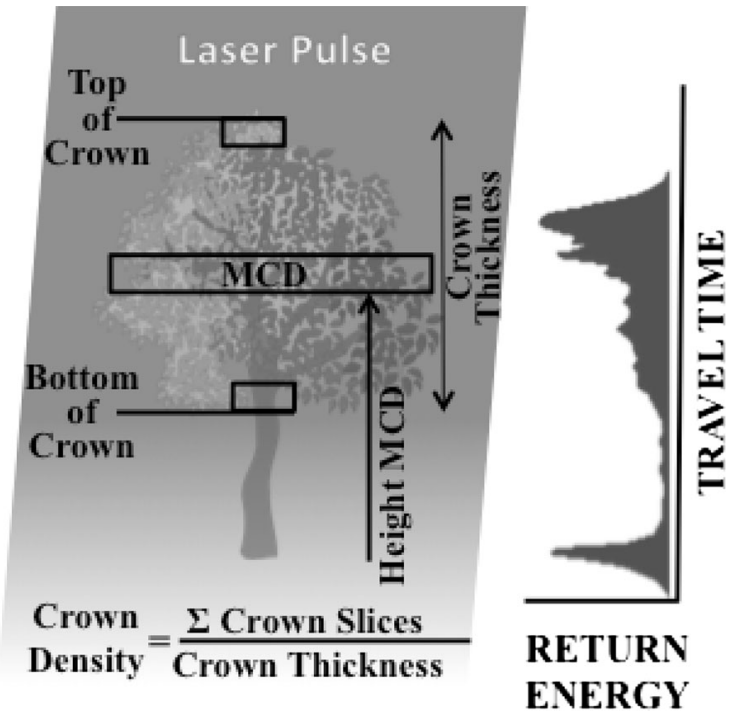

Fig. 2 Measures of forest structure were derived from light detection and ranging (LiDAR) data. LiDAR-derived measures calculated from Top-of-Canopy Height $(\mathrm{TCH})$ at $1.2-\mathrm{m}^{2}$ resolution and aboveground carbon density (ACD) at $10-\mathrm{m}^{2}$ resolution from Mascaro et al. (2010). TCH data was used for the canopy height and distance to gaps. ACD was used to calculate the top of crown and bottom of crown (height of each), Crown Thickness (distance between the top and bottom), crown density (average biomass within the crown), the maximum crown density, and the height of the maximum crown density

weighted mean of each environmental variable was then extracted for all observed and available steps (Fig. 3). Any available steps that projected movements beyond the boundaries of the island were clipped. SSF models were built using the Conditional Logistic (clogit) function in the Survival package in $\mathrm{R}$ (version 2.12.2), which runs a case-control conditional logistic regression that can be cross-validated using the Hab package (Animal Spatial Ecology group; ase-research.org).

We investigated whether the LiDAR-derived forest structure attributes (Table 1) along movement paths with an information-theoretic model selection approach (Burnham and Anderson 2003). We assessed collinearity among forest structure variables by calculating Spearman rank correlation coefficients. As expected, our analysis revealed strong correlation $\left(\mathrm{r}_{\mathrm{s}}>0.8\right)$ existing between 1) the two lateral connectivity variables (gap5m and gap8m); and 2) crown thickness (CrTh) and crown density (CrDen). To minimize collinearity, we developed four separate global models for each species, which contained only non-collinear variables (e.g. gap5m $+\mathrm{CrTh}+$ others; gap8m + CrTh + others; gap5m + CrDen + others; gap8m + CrDen + others). Model selection for each species was based on Akaike's Information Criterion adjusted for small sample size (AICc; Burnham and Anderson 2003). Models were ranked using the difference in AICc score $(\triangle \mathrm{AICc})$ relative to the model with the minimum (best) AICc score. The best model from each species based on AICc and weight of contributing variables were then used for validation (see Tables S2-S4 in Supplementary Materials for full suite of models tested).

The predictive ability of the best-performing models from each species was validated with $\mathrm{k}$-fold crossvalidation using the kfold function in the Hab package in R (Fortin et al. 2009). This technique allows for all the data to be used in both training and testing the model by repeatedly constructing and testing multiple partitions across the whole dataset, which is preferable in cases where replicate movement data are not available (i.e. only a single individual is collared or followed; Fortin et al. 2009). The k-fold crossvalidation approach divides the data into a defined number (k) of groups or "folds." Our data sets were split into tenfolds for a 90-10\% training-testing split. A minimum of 10 repetitions is required in order to ensure that all data are used for both testing and training, but additional repetitions provide a more robust estimate, we used 100 repetitions. In each repetition, observed steps were ranked against random steps and a Spearman's rank correlation $\left(\mathrm{r}_{\mathrm{s}}\right)$ was calculated to evaluate how well the training data explained the testing data. Mean and standard error of $\mathrm{r}_{\mathrm{s}}$ for the best performing model for each species is shown in Table 2.

\section{Results}

Spider and capuchin monkeys were moving much faster (mean speeds of $4.82 \mathrm{~m} / \mathrm{min}, \mathrm{SE}=0.068$ and $5.15 \mathrm{~m} / \mathrm{min}, \mathrm{SE}=0.074$ during active movement, respectively) than did howler monkeys, with a mean speed of just $2.96 \mathrm{~m} / \mathrm{min}$ ( $\mathrm{SE}=0.086$ ) during active movement. Spider and capuchin monkeys also had much longer daily trajectories (mean $=2588 \mathrm{~m}$, $\mathrm{SE}=53.4 \mathrm{~m}$ and mean $=3034 \mathrm{~m}$, mean $=108$, respectively) than did howler monkeys (mean = $424 \mathrm{~m}, \mathrm{SE}=19.3$ ). The range of the spider monkey 
Fig. 3 Simulation of random movement steps for comparison with actual movement steps of animals. Step selection calculates the length-weighted mean of each observed step (dark grey line) relative to five available steps (blue lines) generated from speed and turning angle distributions from observed trajectories. LiDAR-derived measures of forest structure provide spatial heterogeneity along movement paths upon which movement behavior can be characterized. (Color figure online)
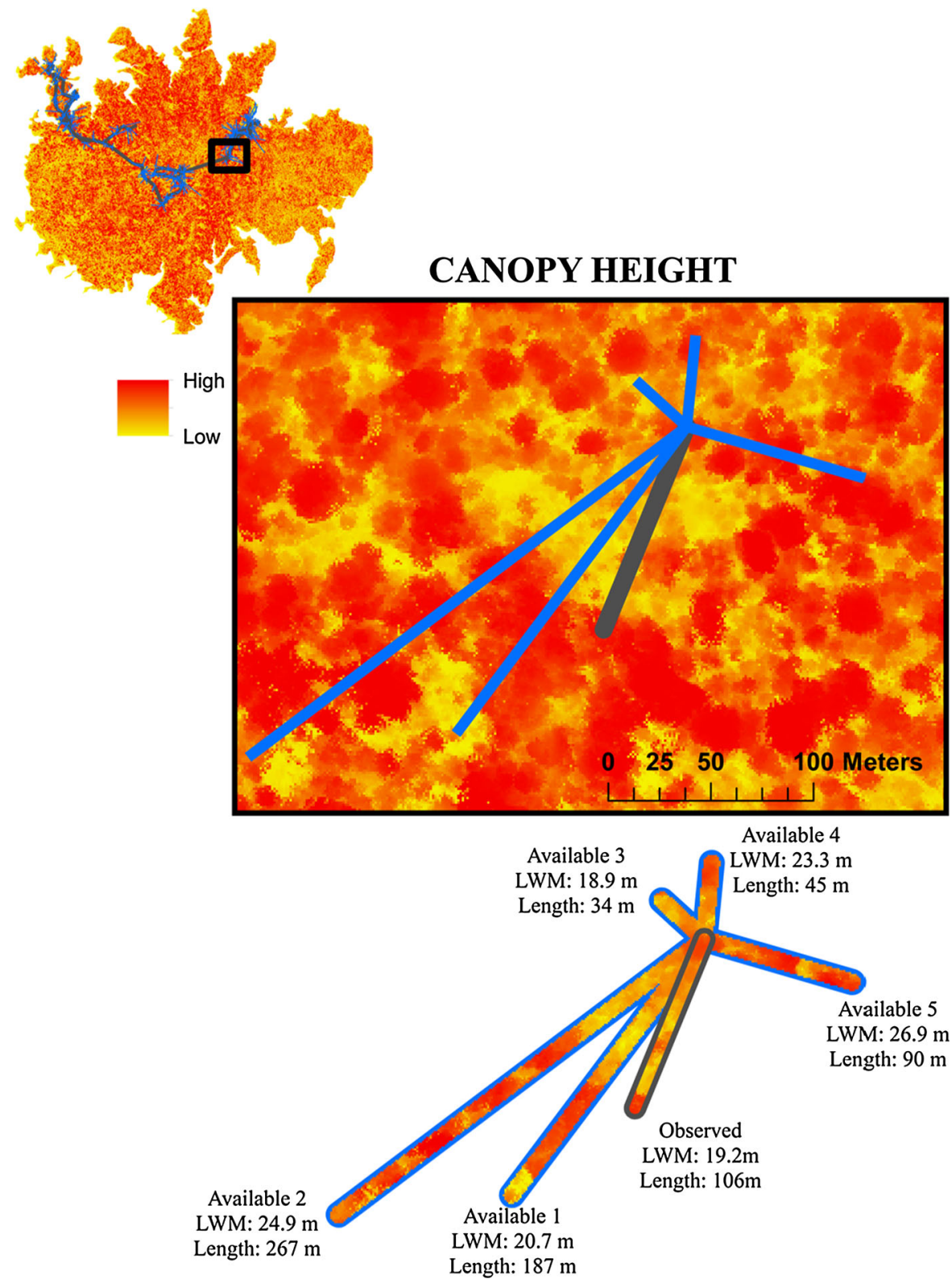

encompassed a large proportion of the island $\left(11.8 \mathrm{~km}^{2}\right)$, which dwarfed the ranges of both capuchin and howler monkeys $\left(0.84\right.$ and $0.66 \mathrm{~km}^{2}$, respectively). The diversity in the speed, distance, and range size of the three species represented three distinct "movement profiles." The high-speed movement through an unconstrained range of the spider monkeys contrasted with the low-speed movement through a constrained range of the howler monkeys. The capuchin monkey, despite being half the size of a spider monkey, moved at equal or greater speeds and distances, though its constrained range was only slightly larger than that of the howler monkeys.

Movement patterns and forest structure

Overall performances of selected models that related movement steps to canopy characteristics differed between the focal species (Table 2). All three species appeared to avoid canopy gaps, as indicated by a strong positive correlation of step selection with distance to gaps. The capuchin monkey selected steps 
with greater distance to gaps at the 5-m cutoff (no LiDAR-detected vegetation above $5 \mathrm{~m}$ ), while howler and spider monkeys selected steps at 8-m cutoff. Step selection was positively related to canopy height for spider and capuchin monkeys, but not for howler monkeys. This indicates that spider and capuchin monkeys preferred the taller canopy that is characteristic of mature forests. Step selection for the howler and spider monkeys was positively correlated with crown thickness, whereas the capuchin step selection was negatively correlated with crown density.

Cross-validation indicated that the spider monkey model was an accurate predictor of selection (mean observed $\left.r_{S}=0.94\right)$, as the observed Spearman rank correlation $\left(r_{S}\right)$ was higher than expected under random selection of movement steps (observed $r_{S} \gg$ random $\mathrm{r}_{\mathrm{S}}$ ). The accuracy of capuchin and howler monkey models was lower (mean observed $r_{S}=0.46$ and 0.31 , respectively), with observed $r_{S}$ values not exceeding $r_{S}$ under random selection of movement steps (Table 2).

\section{Discussion}

Due to the challenge and risk involved in capturing and collaring arboreal species, particularly primates, telemetry data for arboreal primates are not frequently collected. Use of existing telemetry data from single individuals (capuchin and spider monkeys) and ground-based GPS tracking data for a single group undoubtedly limits the conclusions that can be made for entire species, but the high temporal resolution of the trajectories nonetheless provide valuable movement data rarely collected for the focal species. Furthermore, the insight gained from this regarding intraspecific variation in how arboreal habitat is used serves as a call for further investigation of arboreal movement behavior. Movement patterns of arboreal mammals in Neotropical forests are important drivers of seed rain but remain poorly understood due to the complexity of quantifying arboreal habitat structure. We relate detailed movement trajectories of individuals representing three primate species to LiDARderived attributes of canopy structure in order to understand the relationship between movement and canopy structure. All three of the broad categories of forest properties predicted to influence movement behavior (forest maturity, substrate availability, and lateral connectivity) correlated with step selection for both capuchin and spider monkeys, while step selection in howler monkeys was driven by two categories (substrate availability, lateral connectivity). The importance of lateral connectivity fits with biological knowledge of arboreal movement, as crossing gaps is energetically costly (Pontzer and Wrangham 2004; Makin et al. 2012), but the difference in the specific lateral connectivity variables driving models for each species is perhaps even more notable. Two cutoffs were tested to define the maximum height of vegetation to be considered a gap in the canopy; step selection models for the capuchin monkey were much more strongly tied to the 5-m cutoff than the $8-\mathrm{m}$ cutoff. This raises biological questions about each species that would likely require additional data to generalize across species, but the difference in these measures of forest structure and our ability to detect movement preferences between them is quite representative of the nuanced understanding of arboreal movement that high-resolution LiDAR provides.

The importance of canopy structural properties for movement of the three focal species was evident from the model results, particularly for spider monkeys (Table 2; Fig. 4). The importance of canopy structure for spider monkey movement behavior may be related to their locomotor specialization. Their highly route-based travel is undoubtedly related to the way in which they mentally encode space (Di Fiore and Suarez 2007; Palminteri et al. 2012; Trainor et al. 2013; Simonson et al. 2014; Davies and Asner 2014), but our results suggest that selection of structural features is also at play. Semi-brachiation is only possible (or most efficient) in certain types of forest structure, and their selection of mature, intact forest with thick, dense crown vegetation is likely a reflection of that. Spider monkeys may simply be more constrained by forest structure than the more generalist capuchins and howler monkeys and thus are perhaps the best model of the three focal species for environmentally driven movement behavior. The lower accuracy of the capuchin and howler monkey models indicates that the structural features represented in these analyses does not drive movement behavior with the same strength as in spider monkeys. Alternatively, while the resolution of the structural features derived from the Canopy Height dataset (CanHt, Gap8m, Gap5m) is likely fine enough $\left(1 \mathrm{~m}^{2}\right)$ to match the scale at which movement decisions are made, those derived from the Vegetation Density by 
Table 2 Step selection functions for capuchin monkey (Cebus capucinus), howler monkey (Alouatta palliata), and spider monkey (Ateles geoffroyi) on Barro Colorado Island, Panama

\begin{tabular}{|c|c|c|c|c|c|c|c|}
\hline \multirow[t]{2}{*}{ Species } & \multicolumn{5}{|c|}{ Top performing model } & \multicolumn{2}{|l|}{ Accuracy } \\
\hline & Covariate & $\beta$ & SE & $95 \%$ & ce interval & Observed $\overline{\mathrm{r}}_{\mathrm{S}}$ & Random $\overline{\mathrm{r}_{\mathrm{S}}}$ \\
\hline \multirow[t]{3}{*}{ Capuchin monkey } & Canht & 0.028 & 0.0048 & 1.019 & 1.038 & 0.46 (SE 0.032) & $0.053($ SE 0.004$)$ \\
\hline & crden & -0.0053 & 0.0023 & 0.990 & 0.999 & & \\
\hline & gap $5 m$ & 0.0061 & 0.0035 & 0.999 & 1.011 & & \\
\hline \multirow[t]{2}{*}{ Howler monkey } & crth & 0.010 & 0.0068 & 0.997 & 1.024 & 0.31 (SE 0.039) & 0.0022 (SE 0.05) \\
\hline & gap $8 m$ & 0.019 & 0.0065 & 1.006 & 1.032 & & \\
\hline \multirow[t]{3}{*}{ Spider monkey } & canht & 0.062 & 0.0037 & 1.056 & 1.071 & $0.94(\mathrm{SE} 0.071)$ & $0.022($ SE 0.047) \\
\hline & crth & 0.009 & 0.0041 & 1.001 & 1.017 & & \\
\hline & gap $8 m$ & 0.011 & 0.0033 & 1.005 & 1.018 & & \\
\hline
\end{tabular}

Coefficients $(\beta)$ are presented with standard errors (SE) and associated $P$ values. Model accuracy was evaluated using $k$-fold crossvalidation, which was based on observed $\overline{\mathrm{r}}_{\mathrm{S}}$ and $\overline{\mathrm{r}}_{\mathrm{S}}$ expected under random patterns following procedures reported by Fortin et al. (2009). Further details on cross-validation provided in "Materials and methods" section

Height (CrDen, CrTh, MCD, HtMCD) dataset may be too coarse $\left(10 \mathrm{~m}^{2}\right)$. Regardless, the myriad structural variables that can be calculated from high-resolution LiDAR data beyond those included in our analysis and the much finer resolution at which CAO LiDAR can be analyzed in future studies provide great potential for resolving this low model accuracy.
The patterns of our findings expand on and in many ways validate our current understanding of arboreal movement behavior. Hopkins (2011) conducted foundational analysis of howler monkey movement ecology at the scale of a 50-ha experimental plot, and found that the most significant predictor of path establishment was canopy connectivity at $10-20 \mathrm{~m}$

\section{Capuchin Monkey}

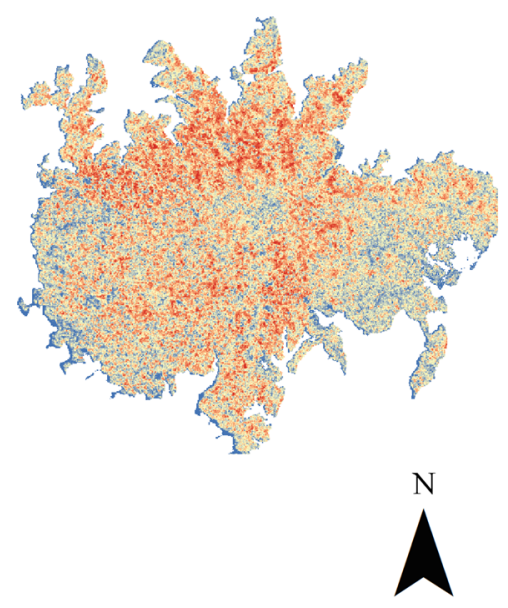

Howler Monkey
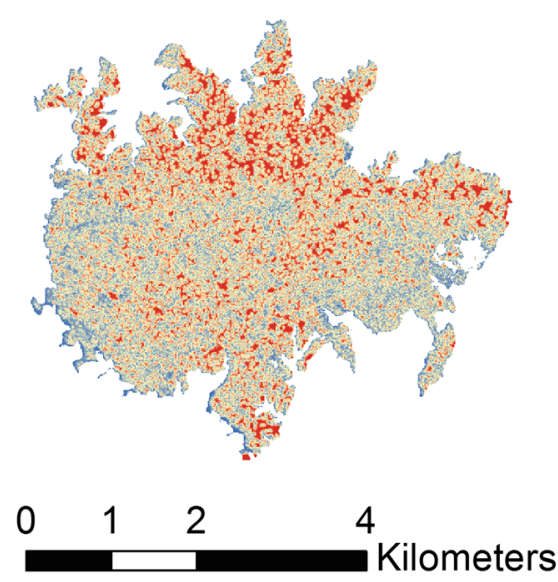

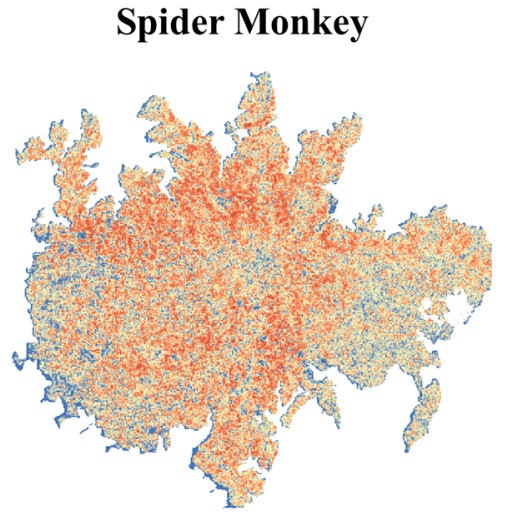

Suitability Index

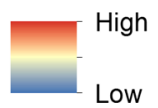

Fig. 4 Maps of suitability of the canopy on Barro Colorado Island, Panama, as predicted by step selection function (SSF) models that related movement trajectories to LiDAR-derived measures of forest structure for three focal primate species. Colors indicate high (red) and low (blue) suitability. Models for all three species were driven by similar measures of forest structure (canopy height, distance to gaps), resulting in similar spatial distributions. Cross-validation (Table 2) showed high accuracy $\left(r_{S}=0.94\right)$ in the spider monkey model than the capuchin and howler monkey models $\left(r_{s}=0.46\right.$ and 0.31 , respectively), indicating that movement behavior was more strongly determined by forest structure in spider monkeys than in the other two species. (Color figure online) 
(i.e. lower canopy). This is consistent with the inverse relationship in our models with canopy height, which indicates selection of lower canopy versus higher canopy. Furthermore, the most significant predictor of repeatedly used paths in the original study was resource availability, which may explain the low overall accuracy of our models, which were driven by forest structure alone. Considering the small daily path lengths and energy constraints of howlers, resource monitoring may be a stronger motivator of movement decisions. Also, given that two consecutive resources are spaced relatively closely compared to the other species, they may not have as many options as other species traveling farther distances. The consistency of our results with previous findings demonstrates the utility of LiDAR-derived characterizations of forests structure at the landscape scale, well beyond the confines of a 50-ha plot. The low overall accuracy of our models in the context of what has been established at this smaller scale, however, highlights the importance of developing landscape-scale resource mapping in order to incorporate resource locations into future analyses.

While the overall performance of step selection models in the three focal species suggests that the importance of forest structure varies based on the characteristics of the species, analysis of the variables within the selected models suggests some degree of similarity in forest properties that may drive step selection. Candidate variables represented forest maturity (canopy height, height of maximum crown density), lateral connectivity (distance to gaps), and substrate availability (crown thickness and density). The generalized features and the variables used to represent them have previously been impossible to represent at the landscape scale. Thus, their measurement by high-resolution LiDAR and inclusion in models of resource selection represents a significant advance in the characterization of arboreal habitat.

The conclusions we can draw from the analysis presented here are meaningful for a landscape-scale understanding of arboreal movement and habitat quality in the forest canopy. Differences in model performance highlight species-specific characteristics of habitat use. Although all three focal species are relatively large-bodied primates, they exhibit great diversity in how they use their spatial and structural environment, which represents the myriad ways in which all non-volant, arboreal species overcome the challenges of moving through a complex, 3-D environment. Similarities in the contributing variables in candidate models shows that there may be some unifying properties in how arboreal habitat quality may be generally defined, but it is clear that a greater sampling of the species and individuals is necessary in order to understand the complex ways in which the use of this habitat is partitioned within the community.

Moving forward in arboreal habitat assessment

How organisms travel through complex 3-D environments in relation to their capacity to move and the available habitat features have rarely been addressed in tropical forests due to the technological constraints associated with quantifying this complexity. Our approach demonstrates how to overcome this limitation using Step Selection Analysis in conjunction with high-resolution LiDAR data and provides a platform from which further analysis can build. The high spatial and temporal resolution of both structure and movement data are a product of the rapid technological advances made in recent years, which give researchers access to the tools necessary for integrative questions. Thus, it is not so much the actual patterns that are observed in step selection by the three species, but rather the fact that selection occurs and that we have the tools to detect it. The forest canopy is not a homogenous mixture of plant tissues through which animals can move randomly as would be suggested from similar analyses with metrics calculated from traditional 2-D remote imagery, but rather a complex, three-dimensional environment that varies widely in its habitat suitability. This has long been recognized (Malcolm 1995; Milton et al. 2005), but the tools at our disposal are only just beginning to capture complexity of the forest canopy at the scale at which its inhabitants perceive it. Beyond the challenge of characterizing arboreal habitat, the dense vegetation of an enclosed forest canopy also inhibit reliable height estimation in biotelemetry devices (R. Kays, pers comm.). For arboreal species in particular, development of telemetry technology that provides reliable 3-D trajectories would also drastically improve our understanding of the habitat selection.

Using high-resolution movement and environmental data, we have used simple, established analytical techniques to assess the relationship between movement behavior and forest structure. Airborne LiDAR 
captures the complex environmental heterogeneity necessary to describe movement behavior relative to forest structure. The LiDAR-derived measures of forest structure has the potential to capture heterogeneous forest conditions across the landscape far more effectively than land classifications and measures of forest quality based on traditional, 2-D remote sensing (see Spatial Heterogeneity in Supplementary Materials). Additional techniques to analyze movement (e.g. state-space models) exist and will continue to evolve as the field of movement ecology develops. Given the substantial size of the arboreal mammal community and the critical role that many species play as key seed dispersers, an understanding of the spatial ecology of mammals within the arboreal environment is critical. This study outlines the means by which we can extend our understanding of habitat quality to incorporate the aboveground environment.

\section{Conclusions}

This study has demonstrated that LiDAR can provide the necessary information required to characterize three-dimensional canopy structure in manner that captures properties relevant to the use of canopy by arboreal mammals. We have also demonstrated that high-resolution remote imaging and biotelemetry can be combined to define quality of the forest canopy as habitat for arboreal mammals, as proposed by Davies and Asner (2014). These accomplishments are highly relevant for a better understanding of the ecology and habitat requirements of arboreal mammals. Tropical forests are subject to many anthropogenic alterations-deforestation, forest fragmentation, climate and land use change-that affect on aboveground connectivity relative to the ground-level environment. This is particularly problematic as current management and conservation plans are not designed to incorporate arboreal habitat (Crofoot 2007; Hopkins 2013; Simonson et al. 2014). Our study provides a means of understanding movement in 3-D environment and highlights the complexity involved in defining arboreal habitat quality.

Acknowledgments This work was supported by the NASA Earth and Space Science Graduate Fellowship (NNX13AO29H) and Yale Institute for Biospheric Studies. We are grateful to Oswald Schmitz, Katherine Mertes, Jennifer Miller, and Colin Donihue for editorial reviews and Roland Kays for providing conceptual support in the early stages of this study. We also benefitted greatly from the comments of two anonymous reviewers. MCC acknowledges support from the Max Planck Institute for Ornithology, the Smithsonian Tropical Research Institute and National Science Foundation grant BCS-1440755. AMT acknowledges support from The Nature Conservancy's NatureNet Science Fellows program. CJC thanks the College of Social and Behavioral Sciences at CSU-Northridge and Stephanie Ramirez for funding and field data collection, respectively. MEH acknowledges support from the National Science Foundation (\#0622611), The Wenner-Gren Foundation, the American Association of University Women, The Leakey Foundation, the Smithsonian Tropical Research Institute, and the University of California at Berkeley. The Center for Tropical Forest Science also provided MEH with georeferenced tree locations on the 50-ha forest dynamics plot, data which were made possible by NSF grants to S. Hubbell, support from CTFS, STRI, the MacArthur Foundation, the Mellon Foundation, the Celera Foundation, and numerous private individuals, and through the hard work of over 100 people. The Carnegie Airborne Observatory is made possible by the Avatar Alliance Foundation, Margaret A. Cargill Foundation, John D. and Catherine T. MacArthur Foundation, Gordon and Betty Moore Foundation, Grantham Foundation for the Protection of the Environment, W.M. Keck Foundation, Mary Anne Nyburg Baker and G. Leonard Baker Jr., and William R. Hearst III.

\section{References}

Anderson-Teixeira KJ, Davies SJ, Bennett AC, Gonzalez-Akre EB, Muller-Landau HC, Joseph Wright S, Abu Salim K, Almeyda Zambrano AM, Alonso A, Baltzer JL, Basset Y (2015) CTFS-ForestGEO: a worldwide network monitoring forests in an era of global change. Glob Change Biol 21:528-549

Asensio N, Brockelman WY, Malaivijitnond S, Reichard UH (2011) Gibbon travel paths are goal oriented. Int J Primatol 14:395-405. doi:10.1007/s10071-010-0374-1

Asner GP, Knapp DE, Boardman J, Green RO, KennedyBowdoin T, Eastwood M, Martin RE, Anderson C, Field CB (2012) Carnegie airborne observatory-2: increasing science data dimensionality via high-fidelity multi-sensor fusion. Remote Sens Environ 124:454-465. doi:10.1016/j. rse.2012.06.012

Asner GP, Knapp DE, Kennedy-Bowdoin T, Jones MO, Martin RE, Boardman J, Field CB (2007) Carnegie airborne observatory: in-flight fusion of hyperspectral imaging and waveform light detection and ranging (wLiDAR) for threedimensional studies of ecosystems. J Appl Remote Sens 1:013536. doi:10.1117/1.2794018

Asner GP, Mascaro J, Muller-Landau HC, Vieilledent G, Vaudry R, Rasamoelina M, Hall JS, van Breugel M (2011) A universal airborne LiDAR approach for tropical forest carbon mapping. Oecologia 168:1147-1160. doi:10.1007/ s00442-011-2165-Z

Boyce MS, Vernier PR, Nielsen SE, Schmiegelow FKA (2002) Evaluating resource selection functions. Ecol Model 157:281-300 
Burnham KP, Anderson D (2003) Model selection and multimodel inference: a practical information-theoretic approach. Springer, New York

Cannon CH, Leighton M (1994) Comparative locomotor ecology of gibbons and macaques: selection of canopy elements for crossing gaps. Am J Phys Anthropol 93:505-524. doi:10.1002/ajpa.1330930409

Carroll G (1980) Forest canopies: complex and independent subsystems. In: Waring RH (ed) Forests: fresh perspectives from ecosystem analysis. Oregon State University Press, Corvallis, pp 87-108

Chapman C (1988) Patterns of foraging and range use by three species of neotropical primates. Primates 29:177-194

Crofoot MC (2007) Mating and feeding competition in whitefaced capuchins (Cebus capucinus): the importance of short- and long-term strategies. Behaviour 144:1473-1495

Crofoot MC, Gilby IC, Wikelski MC, Kays RW (2008) Interaction location outweighs the competitive advantage of numerical superiority in Cebus capucinus intergroup contests. Proc Natl Acad Sci 105:577-581

Crofoot MC, Rubenstein DI, Maiya AS, Berger-Wolf TY (2011) Aggression, grooming and group-level cooperation in white-faced capuchins (Cebus capucinus): insights from social networks. Am J Primatol 73:821-833. doi:10.1002/ ajp. 20959

Davies AB, Asner GP (2014) Advances in animal ecology from 3D-LiDAR ecosystem mapping. Trends Ecol Evol 29:681-691. doi:10.1016/j.tree.2014.10.005

Di Fiore A, Suarez SA (2007) Route-based travel and shared routes in sympatric spider and woolly monkeys: cognitive and evolutionary implications. Anim Cogn 10:317-329. doi:10.1007/s10071-006-0067-y

Di Orio AP, Callas R, Schaefer RJ (2003) Performance of two GPS telemetry collars under different habitat conditions. Wildl Soc Bull (1973-2006) 31:372-379

Emery N, Clayton N (2004) Comparing the complex cognition of birds and primates. In: Rogers L, Kaplan G (eds) Developments in primatology: progress and prospects. Springer, Boston, pp 3-55

Emmons LH, Gentry AH (1983) Tropical forest structure and the distribution of gliding and prehensile-tailed vertebrates. Am Nat 121:513-524

Fortin D, Fortin ME, Beyer HL, Duchesne T, Courant S, Dancose K (2009) Group-size-mediated habitat selection and group fusion-fission dynamics of bison under predation risk. Ecology 90:2480-2490

Guisan A, Thuiller W (2005) Predicting species distribution: offering more than simple habitat models. Ecol Lett 8:993-1009. doi:10.1111/j.1461-0248.2005.00792.x

Hirzel AH, Le Lay G, Helfer V, Randin C, Guisan A (2006) Evaluating the ability of habitat suitability models to predict species presences. Ecol Model 199:142-152. doi:10. 1016/j.ecolmodel.2006.05.017

Hopkins ME (2011) Mantled howler (Alouatta palliata) arboreal pathway networks: relative impacts of resource availability and forest structure. Int J Primatol 32:238-258. doi:10.1007/s10764-010-9464-9

Hopkins ME (2013) Relative dominance and resource availability mediate mantled howler (Alouatta palliata) spatial responses to neighbors' loud calls. Int J Primatol 34: 1032-1054. doi:10.1007/s10764-013-9713-9
Kays R, Allison A (2001) Arboreal tropical forest vertebrates: current knowledge and research. Plant Ecol 153:109-120. doi:10.1023/A:1017585622940

Levin S (1992) The problem of pattern and scale in ecology. Ecology 73:1943-1967

Makin DF, Payne HF, Kerley GI, Shrader AM (2012) Foraging in a 3-D world: how does predation risk affect space use of vervet monkeys? J Mammal 93:422-428

Malcolm JR (1995) Forest structure and the abundance and diversity of neotropical small mammals. In: Lowman MD, Nadkarni NM (eds) Forest canopies. Academic Press, San Diego, pp 179-197

Malcolm JR (2004) Ecology and conservation of canopy mammals. In: Lowman MD, Rinker HB (eds) Forest canopies, 2nd edn. Elsevier Academic Press, Burlington, pp 297-331

Mascaro J, Asner GP, Muller-Landau HC, van Breugel M, Hall J, Dahlin K (2010) Controls over aboveground forest carbon density on Barro Colorado Island, Panama. Biogeosci Discuss 7:8817-8852. doi:10.5194/bgd-7-8817-2010

Milton K (1981) Distribution patterns of tropical plant foods as an evolutionary stimulus to primate mental development. Am Anthropol 83:534-548. doi:10.1525/aa.1981.83.3. $02 \mathrm{a} 00020$

Milton K, Giacalone J, Wright SJ (2005) Do frugivore population fluctuations reflect fruit production? Evidence from Panama. In: Dew JL, Boubli JP (eds) Tropical fruits and frugivores: the search for strong interactors. Springer, Berlin, pp 5-35

Muller-Landau HC, Hardesty BD (2005) Seed dispersal of woody plants in tropical forests: concepts, examples and future directions. In: Burslem D, Pinard M, Hartley S (eds) Biotic interactions in the tropics: their role in the maintenance of species diversity, Cambridge University Press, New York, pp 267-309

Palminteri S, Powell GVN, Asner GP, Peres CA (2012) LiDAR measurements of canopy structure predict spatial distribution of a tropical mature forest primate. Remote Sens Environ 127:98-105. doi:10.1016/j.rse.2012.08.014

Pontzer H, Wrangham RW (2004) Climbing and the daily energy cost of locomotion in wild chimpanzees: implications for hominoid locomotor evolution. J Hum Evol 46:317-335

Russo SE, Augspurger CK (2004) Aggregated seed dispersal by spider monkeys limits recruitment to clumped patterns in Virola calophylla. Ecol Lett 7:1058-1067

Russo SE, Portnoy S, Augspurger CK (2006) Incorporating animal behavior into seed dispersal models: implications for seed shadows. Ecology 87:3160-3174

Simonson WD, Allen HD, Coomes DA (2014) Applications of airborne lidar for the assessment of animal species diversity. Methods Ecol Evol 5:719-729. doi:10.1111/2041210X.12219

Smith RJ, Jungers WL (1997) Body mass in comparative primatology. J Hum Evol 32:523-559

Squires JR, DeCesare NJ, Olson LE, Kolbe JA, Hebblewhite M, Parks SA (2013) Combining resource selection and movement behavior to predict corridors for Canada lynx at their southern range periphery. Biol Conserv 157:187-195. doi:10.1016/j.biocon.2012.07.018

Thurfjell H, Ciuti S, Boyce MS (2014) Applications of stepselection functions in ecology and conservation. Mov Ecol 2:1-12 
Trainor AM, Walters JR, Morris WF, Sexton J, Moody A (2013) Empirical estimation of dispersal resistance surfaces: a case study with red-cockaded woodpeckers. Landscape Ecol 28:755-767. doi:10.1007/s10980-013-9861-5

Vierling KT, Vierling LA, Gould WA, Martinuzzi S, Clawges RM (2008) Lidar: shedding new light on habitat characterization and modeling. Front Ecol Environ 6:90-98. doi:10.1890/070001
Wehncke EV, Domínguez CA (2007) Seed dispersal ecology of non-restricted frugivores, capuchin monkeys in three Neotropical forests. J Trop Ecol 23:519-528. doi:10.1017/ S0266467407004257

Zeller KA, McGarigal K, Whiteley AR (2012) Estimating landscape resistance to movement: a review. Landscape Ecol 27:777-797. doi:10.1007/s10980-012-9737-0 